\title{
PLACVIT PICTVRAS IN ECCLESIA ESSE NON DEBERE: LA PROHIBICIÓN DEL C. 36 PSEUDOILIBERRITANO*
}

\author{
PLACVIT PICTVRAS IN ECCLESIA ESSE NON DEBERE: \\ THE INTERDICTION OF THE PSEUDO-ILIBERRITAN C. 36
}

\author{
Joser VILELLA \\ Universitat de Barcelona \\ vilella@ub.edu \\ ORCID: 0000-0002-1510-1694
}

DOI: $10.1387 /$ veleia. 18080

\begin{abstract}
Resumen: El estudio analítico-comparativo del c. 36 del repertorio pseudoiliberritano pone de manifiesto que este texto veta las representaciones pictóricas vinculadas con la veneración de los santos. Evidencia asimismo que, como los otros preceptos de la «trilogía martirial» —c. 34 y 35- contenida en esta serie, debe datarse a finales del siglo IV o a inicios del v. A partir de tal cronología y hermenéutica, resulta claro que su formulación pretende evitar las figuraciones antropomorfas que entonces empezaban a proliferar en los edificios cultuales cristianos. Inserta en la secular tradición hebraico-cristiana, la corriente "conservadora» plasmada en el c. 36 estaría sucumbiendo ante la ofensiva «idolátrica», avivada, con la complicidad de muchos eclesiásticos valedores de su función didáctica, por las masivas afluencias hacia el cristianismo, con el consiguiente auge del fenómeno martirial.
\end{abstract}

Palabras clave: cánones pseudoiliberritanos, culto martirial, representaciones antropomorfas.

Abstract: The analytical and comparative study of the c. 36 among the pseudo-Iliberritan collection reveals that this text bans the pictorial representations related to the saints' cult. It also demonstrates that, as the other two precepts of the "martyrial trilogy" — c. 34 and 35in this series, it must be dated to the end of 4th century or the beginning of the $5 \mathrm{th}$. According to such a chronology and hermeneutics, it seems clear that its formulation tries to avoid the anthropomorphous representations which started to proliferate in Christian cul-

* La redacción de este texto corresponde, en su literalidad, a la comunicación presentada en el Congreso Internacional de Historia de las Religiones titulado "Homo religiosus. Mediadores con lo divino en el mundo mediterráneo antiguo", celebrado en Palma de Mallorca del 13 al 15 de octubre de 2005, cuyas actas no se han publicado. Se trata de un estudio que se realizó en el marco de los proyectos de investigación HUM2007-61070/ HIST del MEC y 2005SGR-379 de la AGAUR. Las ediciones de las fuentes aparecen señaladas, entre corche- tes, en su primera cita. Cuando corresponden a grandes colecciones con volúmenes numerados, remitimos a ellas mediante las abreviaturas usuales. En los demás casos, mencionamos el nombre del editor, junto con la ciudad y el año de publicación $-\mathrm{o}$, en su caso, la revistaDado que, como hemos indicado, se trata, exactamente, del texto enviado al mencionado congreso internacional, no se han incorporado las ediciones críticas de algunas obras antiguas citadas que han sido publicadas posteriormente, ni, tampoco, citas bibliográficas adicionales. 
tual buildings. In line with the ancient Hebrew and Christian tradition, the "conservative» trend embodied in c. 36 would be declining before the «idolatrous» offensive supported by the complicity of many ecclesiastics who defended its didactic function and strengthened by the massive attendance to Christianism which resulted into a growth of the martyrial phenomenon.

Keywords: pseudo-Iliberritan canons; martyrial cult; anthropomorphous representations.

Recibido: 28-06-2016

Informado: 11-11-2016

Definitivo: 12-01-2017

Una relevante característica de la recopilación pseudoiliberritana ${ }^{1}$ radica en la agrupación de algunos preceptos — o cánones ${ }^{2}$ —, a partir de su temática o de sus destinatarios (ver Vilella 2007, 7-9). Como ya hemos señalado en el estudio dedicado a los c. 34 y 35 (ver Vilella 2008), ambas estipulaciones no sólo comparten el lugar al cual se circunscriben sus prohibiciones —el cimiterium - también obedecen a una misma ratio: impedir determinados comportamientos vinculados con el culto martirial ${ }^{3}$ —el encendido de cirios durante el día y la participación de mujeres en vigilias-. Indicábamos asimismo entonces que esta vía exegética despeja la interpretación de la norma que aparece a continuación, el c. 36, cuyo contenido veta la presencia de imágenes pintadas en los muros de las iglesias: «dispuesto justo después de los mandatos concernientes a prácticas efectuadas in cimiterio, el c. 36 se referiría igualmente — por lo menos en buena medida— a los mártires, cuyas imágenes no consiente in ecclesia, término que, según veremos, puede equivaler a in cimiterio» (Vilella 2008, 472). Entendemos, pues, que tres disposiciones sucesivas del grupo $\mathrm{C}^{4}$ muestran un claro parentesco, siendo su común denominador la oposición a prácticas relacionadas con la veneración de los santos. Presentan los contenidos siguientes ${ }^{5}$ :

cereos per diem placuit in cimiterio non incendi; [inquietandi enim sanctorum spiritus non sunt.] Qui haec non obseruauerint, arceantur ab ecclesiae communione (c. 34).

placuit prohiberi ne feminae in cimiterio peruigilent [, eo quod saepe sub obtentu orationis latenter scelera committant] (c. 35).

placuit picturas in ecclesia esse non debere [; ne quod colitur et adoratur, in parietibus depingatur] (c. 36).

1 Para los resultados facilitados por la crítica textual, ver: Vilella y Barreda 2002, 567-568 y 2006.

2 Aunque no siempre es exacto denominar «cánones» a estos preceptos, seguimos manteniendo tal acepción en aras de la claridad expositiva.

3 El c. 34 presenta una interdicción acompañada de una sanción: se trata, para los bautizados, de una excomunión de duración no especificada. Ver Vilella 2007, 24 y $40-52$.

${ }^{4}$ Dentro de C se incluyen los c. 22-62 y 76-81. Sólo en la primera parte del conjunto $\mathrm{C}$-ubicada entre $\mathrm{A}$ (c. 1-21) y B (c. 63-75) - detectamos relaciones temáticas entre cánones correlativos. Aunque, en realidad, los seis cánones finales podrían desgajarse de las estipulaciones que conforman el grupo C propiamente dicho, preferimos mantener la tripartición establecida en su día por Meigne 1975, 366.
5 Reproducimos la fijación textual de los c. 34-36 que hemos establecido en Vilella y Barreda 2002, 574. A partir del contenido de la Hispana —editada por F. Rodríguez (en Martínez y Rodríguez 1984, IV, 253) —, indicamos, entre corchetes, las adiciones o interpolaciones detectadas.

${ }^{6}$ A nuestro entender, el nec que aparece en la edición crítica de la parte pseudoiliberritana facilitada por la Colección Canónica Hispana debe substituirse por un $n e$ final: ver Vilella y Barreda 2002, 556. Por tanto, la traducción del c. 36 sería: «se ha decidido que no debe haber representaciones pictóricas en la iglesia, para que no se pinte en las paredes lo que se venera y adora». La interpolación existente en la parte final transmitida del c. 36 depende de Ex., 20, 5. 
Nos detendremos ahora en el c. 36, precepto que, por razones de espacio, no pudimos incluir en nuestra anterior investigación. También comparativo y explicativo, este análisis, orgánicamente vinculado con el aplicado a los c. 34 y 35, sigue teniendo como finalidad la comprensión y la datación - necesariamente aproximada - del texto normativo considerado. Con el objetivo de realizar la hermenéutica del c. 36 y de obtener los correspondientes indicios cronológicos, examinaremos y sopesaremos el acervo documental existente en relación con la figuración religiosa cristiana de la Antigüedad Tardía, la única que facilita hitos sólidos para la correcta interpretación de la escueta disposición incluida y glosada en la serie canonística. La mejora en el conocimiento y en la datación de esta unidad textual contribuye, además, a precisar la naturaleza de la compilación pseudoiliberritana.

Un buen conocedor de las prácticas vigentes en las diferentes regiones del Imperio, Eusebio de Cesarea, decía que los edificios cultuales cristianos carecían de representaciones antropomorfas no simbólicas ${ }^{7}$. Así lo expone al explicar a Constancia —entre el 313 y el 324 (ver Thümmel 1984, 214-217) — la imposibilidad de proporcionarle un retrato de Cristo, precisamente la efigie solicitada por la emperatriz al obispo palestino:

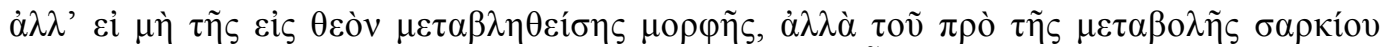

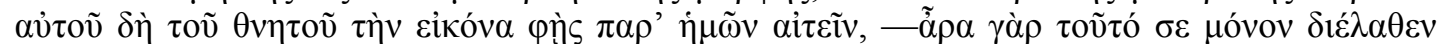

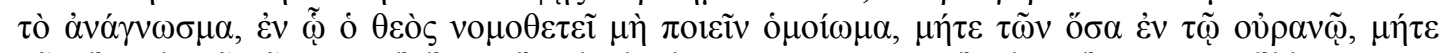

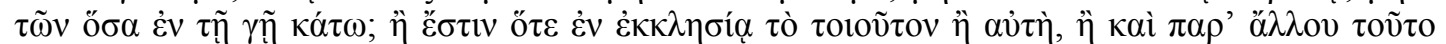

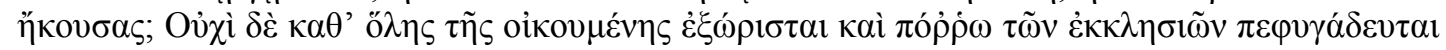

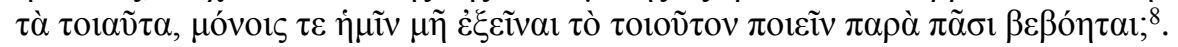

También indica ${ }^{9}$ que algunas personas poseían iconos de Cristo y de los primeros evangelizadores — nunca se refiere, en cambio, a imágenes de mártires que no fueran apóstoles ${ }^{10}$ — : precisamente la tenencia de tales imágenes por particulares había provocado la petición de Constancia

\footnotetext{
7 Abunda la bibliografía relativa a la figuración religiosa de la Antigüedad cristiana, aunque las interpretaciones y conclusiones defendidas en los diferentes trabajos sean, con frecuencia, variadas e, incluso, antagónicas. Ver, entre otros: Dobschütz 1899, 91-97; Kitzinger 1954; Baynes 1955; Grabar 1967; Id. 1968; Thérel 1973; Barnard 1977; Murray 1977; Dagron 1979; Kitzinger 1980; Ŝpidlík 1989; Id. 1991; Tristan, 1996; Brubaker 1998; Delierneux 2001.

8 Eusebius Caes., Ep. ad Const. Aug., c. 1548 [PG 20]. Ver Gero 1981. La oposición a las imágenes constituye una constante en la literatura cristiana anterior a Eusebio de Cesarea. Baste mencionar, a este respecto, la Didascalia apostolorum, los Canones ecclesiastici apostolorum, el De idolatria de Tertuliano, el Octauius de Minucio Félix o el Contra Celsum de Orígenes. Además, la primera patrística rechaza a todos aquellos que pintan motivos paganos: Tertullianus, Adu. Hermog., 1, 2, p. 397 [CCSL 1]; 38, 1, p. 429; Id., Adu. Marc., 2, 9, 4, p. 485 [ibid.]; 2, 22, 1, p. 499, 1. 23-26: proinde et similitudinem uetans fieri omnium, quae in caelo et in terra et in aquis, ostendit et causas, [idolatriae scilicet subs-
}

tantiam cohibentes.] Subicit enim: non adorabitis ea neque seruietis illis [Ex., 20, 5]; Trad. apost., 16, p. 70

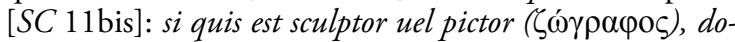

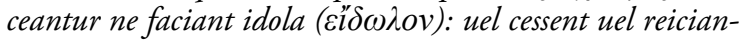
tur.

9 Eusebius Caes., Hist. eccl., 7, 18, 4, p. 672 [GCS NF 6, 2]; Id., Ep. ad Const. Aug., c. 1545-1549. Cf. Augustinus, De haer., 1, p. 290 [CCSL 46].

10 En la biografía correspondiente a Silvestre, el $L i$ ber pontificalis indica que algunos objetos de iluminación donados por Constantino I y colocados ante la tumba de San Lorenzo, en la basílica tiburtina, presentaban escenas de la pasión del mártir: ante corpus beati Laurenti martyris argento clusas sigillis passionem ipsius cum lucernas vi nixis argenteas (Lib. pont., 34, p. 64, 1. 7-8 [MGH gpr 1, 1]). Es prácticamente seguro que tal aseveración fue redactada en época posterior a Silvestre: ver Duchesne $1955^{2}$, xxxiii-xlviii. También se produce desfase cronológico en la Historia Augusta, donde se afirma, sin duda anacrónicamente, que Alejandro Severo tenía una efigie de Cristo: Hist. Aug., Vit. Alex. Seu., 29, 2, p. 594 [Chastagnol, París 1994]. 
(Menozzi 1995, 13). Resultan igualmente explícitos, a este respecto, los testimonios de los Acta Ioannis ${ }^{11}$ y de Juan Crisóstomo, en el De sancto Meletio Antiocheno ${ }^{12}$, además de otros ${ }^{13}$. Cabe, pues, concluir que, a pesar de la costumbre popular, en tiempos de Eusebio, los «retratos» —incluidos los «sagrados»— seguían siendo rechazados por las autoridades eclesiásticas ${ }^{14}$, sin aparecer

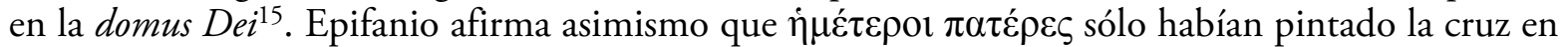
las iglesias ${ }^{16}$, y que los primeros obispos nunca pusieron imágenes — ni de Cristo ni de otros personajes bíblicos - en las cortinas o en las paredes de las iglesias:

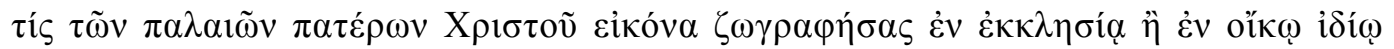

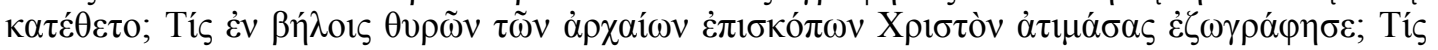

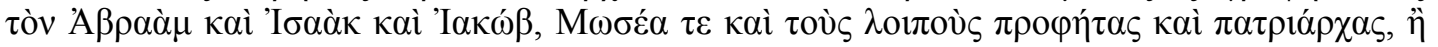

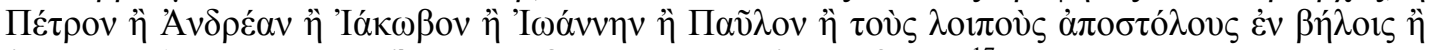

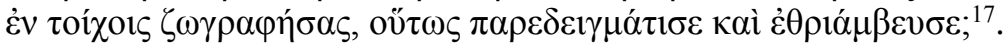

Sin embargo, era ya muy distinta la realidad que existía en el presente vivido por el obispo de Salamina (ver Maraval 1987). En una carta dirigida a Juan de Jerusalén, Epifanio dice:

quando simul pergebamus ad sanctum locum, qui uocatur Bethel, ut ibi collectam tecum ex more ecclesiastico facerem, et uenissem ad uillam, quae dicitur Anablata, uidissemque ibi praeteriens lucernam ardentem et interrogassem, qui locus esset, didicissemque esse ecclesiam et intrassem, ut orarem, inueni ibi uelum pendens in foribus eiusdem ecclesiae tinctum atque depictum et habens imaginem quasi Christi uel sancti cuiusdam; non enim satis memini, cuius imago fuerit. Cum ergo hoc uidissem, in ecclesia Christi contra auctoritatem scripturarum hominis pendere imaginem, scidi illud et magis dedi consilium custodibus eiusdem loci, ut pauperem mortuum eo obuoluerent et efferrent ${ }^{18}$ (...) et deinceps praecipere in ecclesia Christi istius modi uela, quae contra religionem nostram ueniunt, non adpendi ${ }^{19}$.

${ }^{11}$ En el escrito apócrifo denominado Acta Ioannis, se narra que Licomedes, convertido recientemente al cristianismo, hace pintar un retrato de Juan y lo pone en su habitación, cerca de un altar, donde lo engalana con luces y coronas, hecho del que acaba teniendo conocimiento Juan, quien se muestra indignado por ello, pues considera que tiene connotaciones paganas: Acta Ioannis, 26-29, p. 177-181 [CCSL aporr 1]. Este texto ha sido mayoritariamente datado en el siglo II — ver Bovon y Geoltrain (dir.) 1997, 983-, pero también se ha propuesto una cronología de siglo III o IV para el mismo: Galavaris 1981, 14.

12 Iohannes Chrys., De s. Meletio Antioch., 1, c. 516 (BHG 1244) [PG 50].

${ }_{13}$ En el mismo sentido, puede aducirse un diálogo ficticio entre un católico y un hereje a propósito de la veneración de objetos realizados por el hombre - postura que aquél defiende abiertamente en el caso de imágenes correspondientes a mártires—. Alexakis 1998 ha editado y comentado este texto, además de datarlo en el segundo tercio del siglo v. Cf. asimismo Augustinus, De haer., 7, p. 294.

${ }_{14}$ Eusebio de Cesarea condena, por ejemplo, explícitamente la costumbre pagana de venerar las imágenes de los fallecidos: Eusebius Caes., Vit. Const., 1, 3, 2, p. 16 [GCS NF 6, 3].

15 Krautheimer 1967, 120, considera que en Occidente la primera decoración figurativa mural de una iglesia corresponde a la traditio legis musiva de San Pedro del Vaticano, datada después del 357.

16 Epiphanius Constant., Ep. ad Theod. imp., p. 185, 1. 59-61 [Thümmel, ByzSlav, 47, 1986]: kà̀

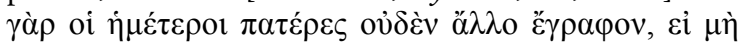

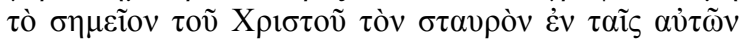

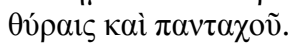

17 Epiphanius Constant., Ep. ad Theod. imp., p. 185, 1. 21-27. Cf. Id., Tract. c. eos qui imagines faciunt,

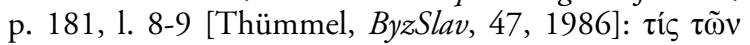

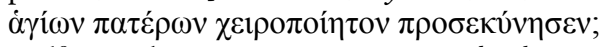

18 Epiphanius Constant., Ep. ad Iohan. Hierosol., 9, apud Hieronymus, Ep., 51, p. 411, 1. 4-15 [CSEL 54]. Esta epístola se ha conservado en la traducción latina efectuada por Jerónimo durante la controversia origenista.

19 Epiphanius Constant., Ep. ad Iohan. Hierosol., 9, apud Hieronymus, Ep., 51, p. 411, 1. 22-24. Cf. Id., Adu. haer., 27, 9-10, p. 310-311 [GCS 25], donde se refiere a la veneración secreta de imágenes de Cristo. 
Resulta explícito el relato de Epifanio: al entrar, durante el año $393^{20}$, en la iglesia de Anablata, localidad palestina, ve una cortina teñida con una imagen de Cristo o de algún santo ${ }^{21}$ —el obispo de Salamina no identifica con exactitud la efigie antropomorfa masculina- Enojado por la ubicación de esta hominis imago, rasga el velo. Del suceso parece colegirse que, mientras en las iglesias de Chipre no estaban permitidas las representaciones de Cristo o de los mártires, estas figuraciones ya debían ser entonces frecuentes en la circunscripción de Juan, obispo abiertamente favorable al culto martirial ${ }^{22}$.

Ante la permisividad mostrada por algunos colegas suyos ante la confección de imágenes y su ubicación-veneración en iglesias, Epifanio lleva a cabo una auténtica cruzada para acabar con esta nueva ofensiva idolátrica ${ }^{23}$. Escrito poco después del incidente de Anablata, su panfleto en contra de quienes realizaban figuraciones contiene diferentes argumentos para sustentar el carácter novedoso y pagano de la proliferación de imágenes «sagradas» que entonces acontecía en las iglesias cristianas:

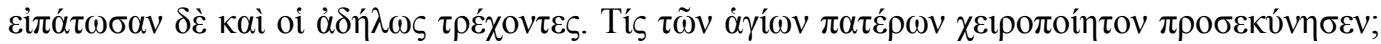

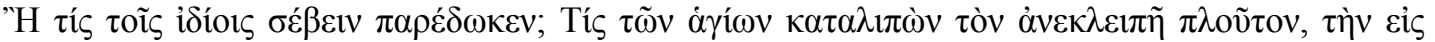

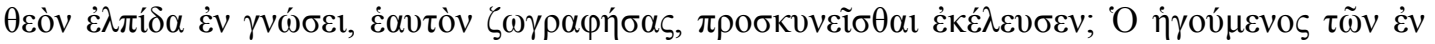

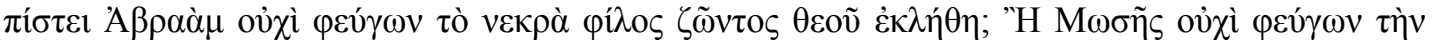

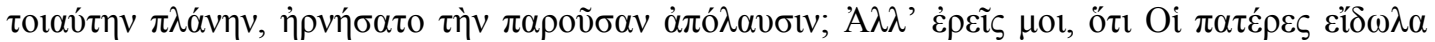

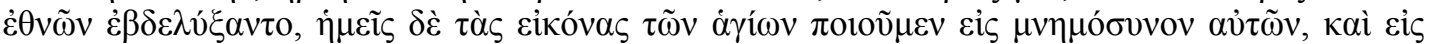

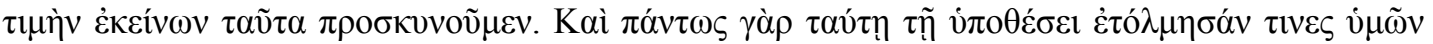

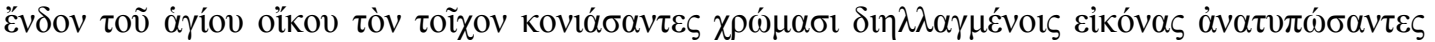

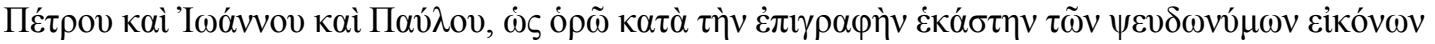

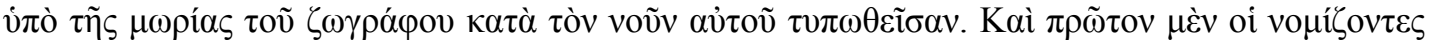

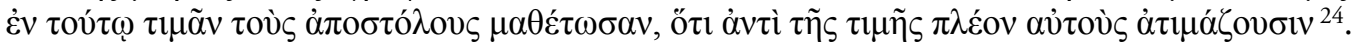

No sólo recurre a las Escrituras y a la tradición secular, contraponiendo el pasado al presente respecto a las imágenes de personajes sagrados utilizadas con una finalidad cultual, Epifanio tampoco acepta que las figuraciones sirvieran — como sin duda afirmarían sus valedores - únicamente para honrar a los santos - y no para venerarlos_- y reprueba que en las paredes de las iglesias hubiera imágenes polícromas, además de considerarlas "falsas», habida cuenta de que han sido elaboradas por un determinado pintor según su propio - y necio - parecer, hecho que, siempre según el chipriota, contribuye a deshonrar todavía más a los supuestamente representados ${ }^{25}$. Para un de-

20 Para la cronología, ver Cavallera I, 1, 1922, 206214; I, 2, 1922, 33.

21 El Peregrino de Piacenza narra - hacia el 560/570 - que en Menfis existía un pallium lineum con la imagen del Salvador: Anonymus Placent., Itiner., 44, p. 152, 1. 8-12 [CCSL 175].

${ }_{22}$ Lucianus presb. (et Auitus Brac.), Ep. de inuen. corp. s. Steph. mart., 35, p. 208-210 [Vanderlinden, REByz 4, 1946]; 44-48, p. 214 —cf. Basilius Seleuc., Serm., 41, 468-469 [PG 85]-. Cf. Sozomenus, Hist. eccl., 9, 16-17, p. 407-408 [GCS 50]. Ver Vilella 2000, $112-115$.

23 Atribuye esta embestida al mismo Satanás: Epiphanius Constant., Tract. c. eos qui imagines faciunt, p. 182, 1. 60; Id., Ep. ad Theod. imp., p. 184, 1. 2-6.
${ }^{24}$ Epiphanius Constant., Tract. c. eos qui imagines faciunt, p. 181, 1. 8-24. Resultan significativas las referencias a Abraham, Moisés y a los Padres de la Iglesia.

${ }^{25}$ El obispo chipriota también se refiere a las falsas imágenes en el libelo enviado a Teodosio I: $\ddot{\alpha} \mu \alpha$

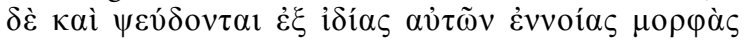

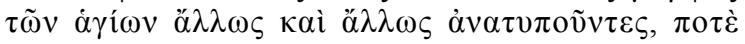

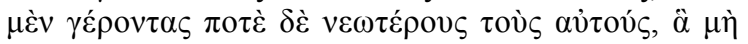

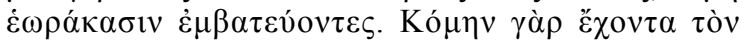

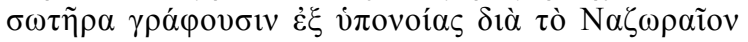

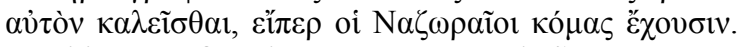

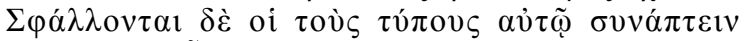

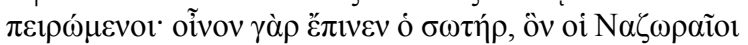

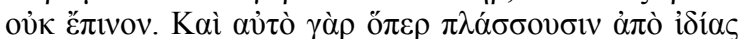

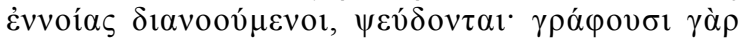


fensor de la tradición hebraico-cristiana, antiidolátrica, resulta evidente que las representaciones no simbólicas ${ }^{26}$ de Cristo — normalmente pictóricas- constituían un oprobio todavía mayor, al cual también se refiere Epifanio ${ }^{27}$.

En su afán por mantener a los cristianos alejados de las prácticas idolátricas, el obispo de Salamina también eleva una petición a Teodosio I — quien entonces ya había legislado en contra de las herejías y del paganismo ${ }^{28}$ — para que el emperador atajara con severidad el mal de las imágenes «sagradas»:

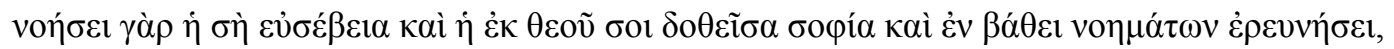

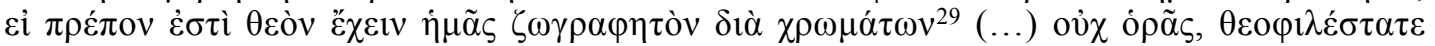

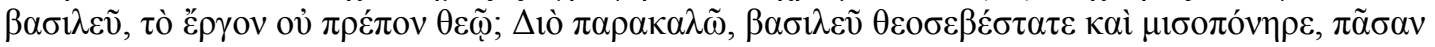

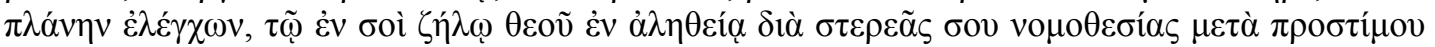
ó

Muy claro y concreto se muestra Epifanio cuando solicita a Teodosio I la retirada de las cortinas que tienen pinturas «embusteras» —en iglesias, baptisterios, martyria y casas-, el blanqueado de las paredes con imágenes — sobre todo en las iglesias—, y la eliminación de las representaciones musivas - por lo menos siempre que sea posible-:

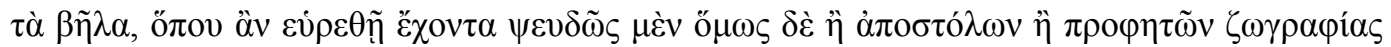

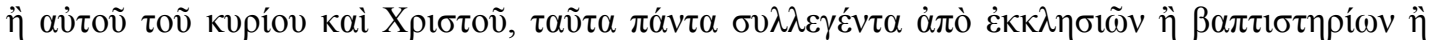

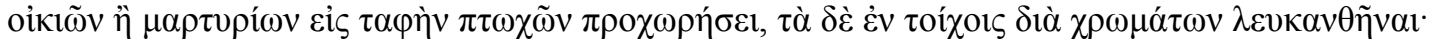

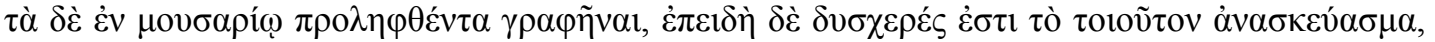

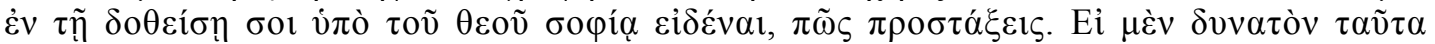

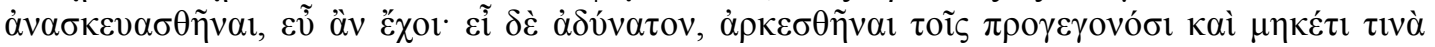
$\zeta \omega \gamma \rho \alpha \varphi \varepsilon \tilde{v}$ oข̃ $\omega \varsigma^{31}$.

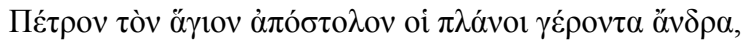

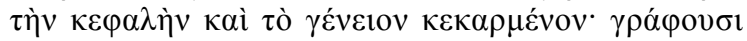

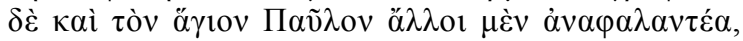

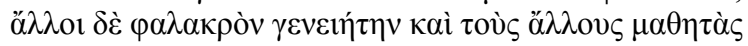
$\psi 1 \lambda \tilde{\omega} \varsigma \kappa \varepsilon \kappa \alpha \rho \mu \varepsilon ́ v o v \varsigma$ (Epiphanius Constant., Ep. ad Theod. imp., p. 185, 1. 27-39).

26 Es claramente simbólica la figura del Buen Pastor. Ver n. 36.

27 Epiphanius Constant., Tract. c. eos qui ima-

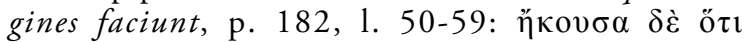

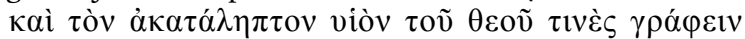

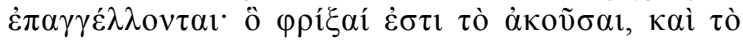

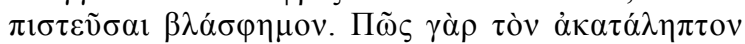

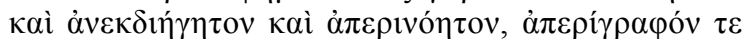

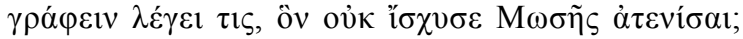

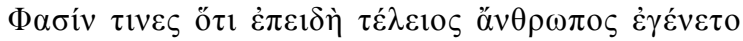

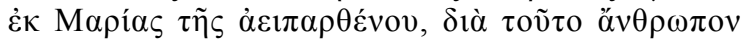

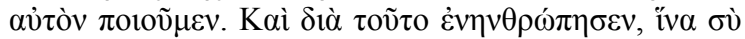

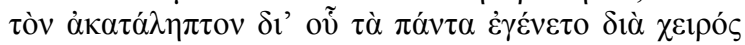

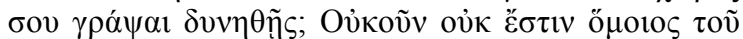

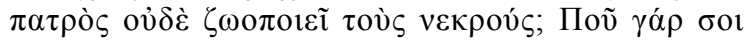

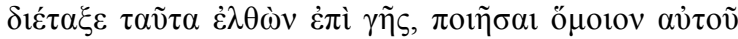

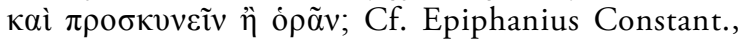
Ep. dogmatica [frag.], p. 184 [Thümmel, ByzSlav, 47,

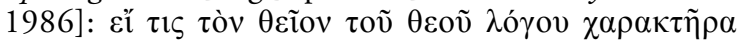

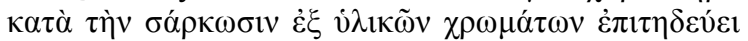
$\kappa \alpha \tau \alpha \nu$ ๆ̃ $\sigma \alpha 1$. Epifanio nunca se refiere a la existencia de «imágenes» del Dios Padre, sólo del Encarnado.

${ }_{28} \mathrm{Al}$ parecer, Epifanio pretendía que Teodosio I legislara en contra de las imágenes como continuación de su política antipagana, y opuesta a todo cristianismo no

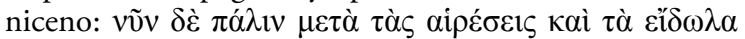

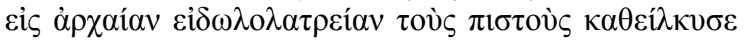

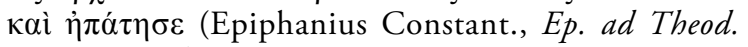
imp., p. 184, 1. 4-6).

29 Epiphanius Constant., Ep. ad Theod. imp., p. 184, 1. 6-8.

30 Epiphanius Constant., Ep. ad Theod. imp., p. 185, 1. 46-50. Pide a Teodosio I «una legislación dura» al respecto.

31 Epiphanius Constant., Ep. ad Theod. imp., p. 185, 1. 50-59. Es significativa la referencia a los martyria. 
Aunque el obispo de Salamina no consiguió el favor imperial para su petición, en el testamento que dirige a sus feligreses les sigue pidiendo que no ubiquen ninguna imagen en las igle-

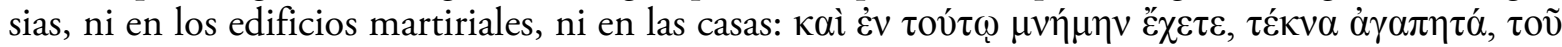

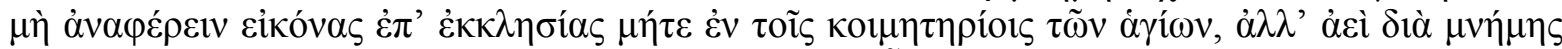

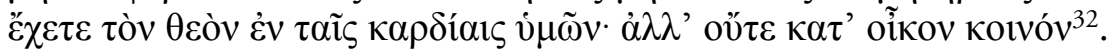

El testimonio de Epifanio no sólo permite constatar que las representaciones antropomorfas personalizadas ya se habían introducido en los edificios cultuales cristianos, también evidencia el debate que entonces existía a este respecto entre los propios eclesiásticos. Había finalizado el consenso, el convencimiento secular de que las Escrituras no permitían las imágenes "realistas»: la tendencia popular estaba ganando terreno al primigenio y radical rechazo de las prácticas consideradas idolátricas, repudio que todavía se mantenía en época de Eusebio de Cesarea. Se trata de un relevante cambio de valores que, a finales del siglo Iv, incluso era fomentado por algunos obispos. Resulta evidente que, en esta coyuntura, la voz del obispo chipriota no sería la única que abogaría por el mantenimiento de la prohibición veterotestamentaria ${ }^{33}$.

Durante el Imperio romano cristiano, amplios sectores eclesiásticos continuarían oponiéndose a la creciente práctica de involucrar a las imágenes antropomorfas en el culto, sobre todo —aunque no únicamente - martirial, a pesar de que ya fuera difícil contener el empuje popular —agrandado por las masivas afluencias hacia el cristianismo y por la paulatina debilidad del paganismo- $y \mathrm{de}$ que algunos eclesiásticos considerasen más provechoso amoldarse a los nuevos tiempos y canalizar en clave cristiana esta religiosidad ancestral y multitudinaria ${ }^{34}$. Quienes, durante los Christiana tempora, se mantenían en la línea de Eusebio y de todos aquellos que se habían opuesto, una y otra vez, a las prácticas idolátricas desde mucho antes ${ }^{35}$ no debían condenar las figuras o elementos simbólicos $^{36}$-ya tradicionales entre los cristianos ${ }^{37}$ - tampoco determinadas escenas bíblicas interpretadas salvíficamente ${ }^{38}$. Sí se mostrarían contrarios, en cambio, a las representaciones humanas

32 Epiphanius Constant., Testam. ad ciues [frag.], p. 252 [CCSG 33]. Justo antes de este pasaje, Epifanio exhorta a su comunidad a mantener las tradiciones recibidas.

33 Así lo ha señalado acertadamente Menozzi 1995, 15.

34 Ver, por ejemplo, Brown 1983, 40-43.

35 Ver n. 7 y 8

36 Como es sabido, en el primer arte cristiano - siglos I-II - sólo aparecen representaciones simbólicas e ilustraciones de pasajes bíblicos —éstas a partir del siglo III-, tanto del Antiguo como del Nuevo Testamento. Resulta significativo Clemens Alex., Paedag., 3, 59, 2,

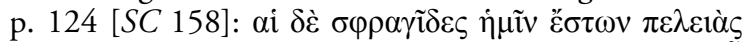

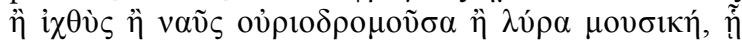

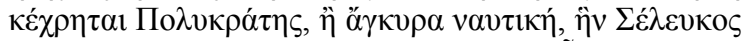

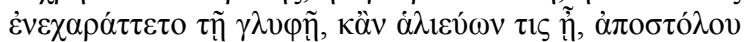

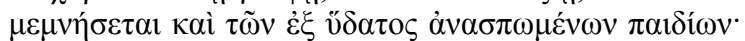

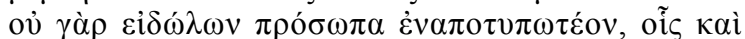

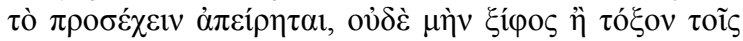

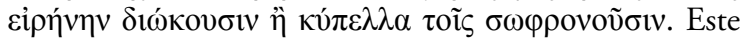
pasaje pone de manifiesto que la figura humana también se halla entre los símbolos pictóricos —aunque nunca con una finalidad cultual ni entendida como una especie de «retrato»— utilizados por los cristianos del
Imperio pagano. Tertuliano atestigua que el Buen Pastor era representado asimismo en cálices litúrgicos: Tertullianus, De pud., 10, 12, p. 200 [SC 394]. Cf.: Augustinus, Tract. in eu. Ioannis, 24, 2, p. 245, 1. 16-19 [CCSL 36]; Id., De doctr. Christ., 1, 2, p. 7, 1. 8-10 [CCSL 32]; 2, 1, p. 32, 1. 5-8.

37 Es ingente la bibliografía acerca de la iconografía del arte cristiano preconstantiniano. Ver, por ejemplo: Rice 1957; Croquisson 1964; Grabar 1967; Thérel 1973; Giordani 1977; Finney 1977; Id. 1987/1988, 216-222; Bisconti 1989; Prigent 1991; Bigham 1992; Bisconti 2000. Resulta asimismo significativo que el emperador Constantino I utilizara símbolos cristianos, y no representaciones «realistas» de Cristo: Eusebius Caes., Vit. Const., 3, 3, p. 82; 3, 49, p. 104; Id., Hist. eccl., 9, 9, 10-11, p. 832. Ver Grigg 1977.

38 Tales representaciones del Antiguo y Nuevo Testamento aparecen con frecuencia en las catacumbas romanas a partir del siglo III. Ver, por ejemplo: Ferrua 1960; Kötzsche Breitenbruch 1976; Guyon 1987; Carletti 1989; Février 1989; Bargebuhr 1991; Fiocchi Nicolai-Bisconti-Mazzoleni 1999. En el 383, Gregorio de Nisa indica que ha visto muchas veces la representación realista del sacrificio de Abraham: Gregorius Nyss., De 
que ni eran alegóricas ni formaban parte de un pasaje escriturístico: así se constata en los textos aducidos de Eusebio y Epifanio ${ }^{39}$.

Agustín también compartía, inicialmente, esta corriente tradicionalista y rigorista. En el 388 (ver Perler y Maier 969, 432-433), escribe:

nolite mihi colligere professores nominis Christiani neque professionis suae uim aut scientes aut exhibentes. Nolite consectari turbas imperitorum, qui uel in ipsa uera religione superstitiosi sunt uel ita libidinibus dediti, ut obliti sint quid promiserint deo. Noui multos esse sepulcrorum et picturarum adoratores. Noui multos esse qui cum luxuriosissime super mortuos bibant et epulas cadaueribus exhibentes super sepultos seipsos sepeliant et uoracitates ebrietatesque suas deputent religioni ${ }^{40}$.

Las representaciones pictóricas de mártires eran consideradas, pues, idolátricas por el joven Agustín. En su De consensu euangelistarum — compuesto hacia el 400 (ver Perler y Maier 1969, 444-445)—, el obispo de Hipona sigue mostrándose contrario a las imágenes. Alude ahora a las de Cristo y de Pedro y Pablo — ya mencionadas por Epifanio ${ }^{41}$ _ y, asimismo como éste, lamenta que los ingenuos prefieran conocer a los apóstoles a través de embusteras pinturas murales, en lugar de acudir al Nuevo Testamento: et occurrit eis Petrus et Paulus, credo, quod pluribus locis simul eos cum illo pictos uiderent, quia merita Petri et Pauli etiam propter eundem passionis diem celebrius sollemniter Roma commendat. Sic omnino errare meruerunt, qui Christum et apostolos eius non in sanctis codicibus, sed in pictis parietibus quaesierunt, nec mirum, si a pingentibus fingentes decepti sunt ${ }^{42}$. Resulta claro que, en este pasaje —y probablemente también en el anterior-, Agustín se refiere a los engaños pictóricos ubicados en paredes de edificios cultuales cristianos.

Sin embargo, este posicionamiento — antiguo y anclado en los preceptos bíblicos ${ }^{43}$ — había entrado definitivamente en crisis, sobre todo a causa del calado que estaba adquiriendo el culto mar-

deitate filii et spir. sancti, c. 572 [PG 46]. En el Contra Faustum Manichaeum —refutación escrita entre el 397 y el 404 (ver PCBE, I, 390-397, Faustus 2)-, el mismo Agustín sigue aceptando con naturalidad este tipo de figuraciones: Abraham si filium sponte immolaret, quid, nisi horribilis et insanus, deo autem iubente, quid, nisi fidelis et deuotus adparuit? [cf. Gen., 22, 10] Quod usque adeo ipsa ueritas clamat, ut eius noce deterritus Faustus, cum in ipsum Abraham, quid diceret, unguibus et dentibus quaerens usque ad calumniosum mendacium perueniret, hoc tamen reprehendere non auderet, nisi forte non ei ueniret in mentem factum ita nobile, ut et non lectum nec quaesitum animo occurreret, ut denique tot linguis cantatum, tot locis pictum et aures et oculos dissimulantes feriret (Augustinus, C. Faust. Manich., 22, 73, p. 671, 1. 2-11 [CSEL 25, 1]). Cf. Cyrillus Alex., Ep. ad Acacium episc. Scythop., 22, p. 48, 1. 11-13 [ACO 1, 1, 4].

39 Ver n. 8, 14, 16-19, 23-25, 27 y 29-32.

40 Augustinus, De mor. eccl. cathol. et de mor. Manich., 1, 34, 75, p. 80, 1. 10-18 [CSEL 90]. En el De fide et symbolo, sigue oponiéndose a los simulacra —en este caso se refiere a las representaciones de Cristo-: Augustinus, De fide et symb., 14, p. 16, 1. 15-21 [CSEL 41].
41 Ver n. 17 y 24-25. Jerónimo indica que en las saucomariae solía representarse a los apóstoles: Hieronymus, Comment. in Ionam, 4, 6, p. 298 [SC 323].

42 Augustinus, De cons. eu., 1, 10, 16, p. 15-16 [CSEL 43]. En relación con la opinión que el hiponense tenía de las artes figurativas, ver: Augustinus, De doctr. Christ., 2, 36, p. 58-60; 2, 39, p. 61, 1. 20-25.

43 Ex., 20, 4: non facies tibi sculptile, neque omnem similitudinem quae est in caelo desuper, et quae in terra deorsum, nec eorum quae sunt in aquis sub terra. Dt., 4 , 15-18: custodite igitur sollicite animas uestras. Non uidistis aliquam similitudinem in die, qua locutus est uobis Dominus in Horeb de medio ignis: ne forte decepti faciatis uobis sculptam similitudinem, aut imaginem masculi uel feminae. Cf.: Minucius Felix, Octau., 32, 1-2, p. 55 [Waltzing, Leipzig 1926]: putatis autem nos occultare quod colimus, si delubra et aras non habemus? Quod enim simulacrum deo fingam, cum, si recte existimes, sit dei homo ipse simulacrum? Templum quod ei extruam, cum totus hic mundus eius opere fabricatus eum capere non possit? Et cum homo latius maneam, intra unam aediculam uim tantae maiestatis includam? Nonne melius in nostro dedicandus est mente? In nostro immo consecrandus est pectore?; Eusebius Caes., Ep. ad Const. Aug., c. 1548: غ̇v 
tirial. En plena época de creciente proliferación y veneración popular de santos ${ }^{44}$, las imágenes a ellos vinculadas adquieren una función — también mediadora — que, en la práctica y para muchos devotos, no dista mucho de la atribuida a las mismas reliquias que representan ${ }^{45}$. A causa, básicamente, de la influencia del donatismo y del incremento de las partículas de San Esteban en África después del $418^{46}$, el propio Agustín acaba modificando su actitud hacia los restos santos y sus representaciones pictóricas, cambio que se muestra acorde con los tiempos que corrían ${ }^{47}$.

A este respecto, también es significativo el testimonio facilitado por el De miraculis sancti Stephani, opúsculo compuesto entre el 418 y el 426/427 a instancias del obispo Evodio de Uza$\operatorname{lis}^{48}$. Narra que, delante de la memoria del protomártir construida en Uzalis, había una tela con dos escenas de San Esteban relacionadas con su victoria sobre el dragón:

dedit ergo subdiacono ${ }^{49}$ memorato uelum uariis pictum coloribus, in quo inerat pictura haec: in dextera ueli parte ipse sanctus Stephanus uidebatur astare, et gloriosam crucem propriis repositam humeris baiulare, qua crucis cuspide portam ciuitatis uidebatur pulsare, ex qua profugiens draco teterrimus

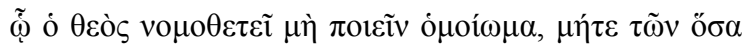

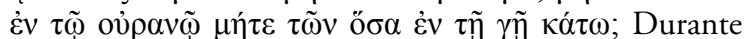
el siglo IV, los $\alpha v \theta \rho \omega \pi о \mu о \rho \varphi \tilde{\eta} \tau \alpha$ s se oponen a la exégesis origenista: nempe contra anthropomorphitas, qui simplicitate rustica Deum habere membra, quae in diuinis libris scripta sunt, arbitrantur, furens et indignans loquebaris (Hieronymus, C. Ioannem Hierosol., 11, c. 364 [PL 23]).

44 Scilicet post persecutiones tam multas tamque uehementes cum facta pace turbae gentilium in christianum nomen uenire cupientes hoc impedirentur, quod dies festos cum idolis suis solerent in abundantia epularum et ebrietate consumere nec facile ab his perniciosissimis sed tamen uetustissimis uoluptatibus se possent abstinere, uisum fuisse maioribus nostris, ut huic infirmitatis parti interim parceretur diesque festos post eos, quos relinquebant, alios in honorem sanctorum martyrum uel non simili sacrilegio quamuis simili luxu celebrarent (...) quocirca iam tempus esse, ut, qui non se audent negare christianos, secundum Christi uoluntatem uiuere incipiant, ut ea, quae, ut essent christiani, concessa sunt, cum christiani sunt, respuantur (Augustinus, Ep., 29, 9, p. 120 [CSEL 34, 1]). Cf. Gregorius Nyss., De uita Gregorii Thaumaturgi, c. 953 (BHG 715-715b) [PG 46]. Un proceso parecido se documenta entre los anglos convertidos al cristianismo durante el pontificado de Gregorio Magno: Gregorius I, Ep., 11, 56, p. 961-962 (Jaffé, 1848) [CCSL 140A]. Ver: Delehaye $1927^{3}$, 151; Id. $1933^{2}$, 416; HerrmannMascard 1975, 17.

45 Gregorius Naz., Carm. moral., 1, 2, 10, c. 738 [PG 37], denomina $\sigma \varepsilon \beta \alpha \sigma \mu i ́ \alpha$ a la imagen de San Polemón. Por su parte, Paulinus Nol., Ep., 32, 3, p. 278, 1. 5 [CSEL 29], dice: Martinum ueneranda uiri testatur imago.

46 El mismo Agustín indica que en África hubo diversas llegadas de restos del protomártir: Augusti- nus, Serm., 318, 1, c. 1438 [PL 38]; Id., Serm., 317, 1, c. 1435 [ibid.]. Cf. asimismo: Gennadius, De uir. ill., 40, p. 76, 1. 15 [TU 14, 1a]; Marcellinus (comes), Chron., a. 416, p. $73[M G H$ ad 11, Chronica minora 2]. Las reliquias de San Esteban —muy abundantes en el Norte de África durante los años veinte del siglo vno se hallan en Hipona hasta el invierno del 424/425: Augustinus, De ciu. Dei, 22, 8, p. 824, 1. 353-354 [CCSL 48]. Ver: Delehaye 1925, 74-85; Saxer 1980, 254-278.

47 Augustinus, Serm., 316, 5, c. 1434 [PL 38]: dulcissima pictura est haec, ubi uidetis sanctum Stephanum lapidari, uidetis Saulum lapidantium uestimenta seruantem. La evolución doctrinal de Agustín en relación con los milagros permite constatar tanto la rápida progresión que entonces tuvo el culto martirial como su incentivación episcopal, incluso por obispos que previamente se habían mostrado reticentes a este respecto. Ver: Vooght 1939; Courcelle 1968², 139-153; Saxer 1980, 239-244 y 295-296; Duval 2006. Cf. Bavel 1995.

48 Las reliquias de San Esteban no se documentan en Uzalis - la primera ciudad africana en disponer de estos restos (Augustinus, De ciu. Dei, 22, 8, p. 824, 1. 360-362) - antes del 418. En efecto, las reliquias del santo llegaron a esta ciudad unos cuarenta días antes de ser trasladadas a su iglesia, efeméride en la que se lee la carta de Severo de Menorca (De mirac. s. Steph. protomart. libri, 1, 2, c. 835 [BHL 7860] [PL 41]), fechada después del 9 de febrero del 418: Seuerus Minor., Ep. de conu. Iud. apud Minor. ins. mer. s. Steph. facta, 31, 1, p. 64 (BHL 7859) [Amengual, Palma de Mallorca 1992]. En relación con los De miraculis sancti Stephani protomartyris libri, ver PCBE, I, 366-373, Euodius 1. Ver asimismo Saxer 1980, 246-254.

49 Ver PCBE, I, 1059, Sennodus. 
cernebatur exire, amico Dei uidelicet aduentante. Verum ille serpens noxius nec in ipsa fuga tutissimus, sub triumphali pede martyris Christi contritus aspiciebatur et pressus. Talis itaque pictura ueli non omnino absque mysterio Dei ubi a memorato subdiacono allata pariter atque suspensa est ante ipsam memoriam tanti patroni, omnis aetas omnisque sexus intueri et mirari coepit, tanquam spectaculum grande, quo scilicet auctore quoue liberatore draco ille exstinctus est hostisque deuictus ${ }^{50}$.

Resulta reveladora la distinta suerte de los velos de Anablata y Uzalis: el obispo Epifanio había arrancado el primero por creer que su rostro constituía algo idolátrico; el segundo glosa y transmite el milagro del protomártir con el beneplácito del obispo Evodio. La actitud negativa y prohibitiva acaba cediendo el paso a la positiva y permisiva, con la paulatina aparición de programas iconográficos en las iglesias, tanto en el episcopado oriental como en el occidental ${ }^{51}$. A este respecto, los testimonios griegos más antiguos de que disponemos son las justificaciones que de estos ciclos hacen los capadocios - Basilio de Cesarea ${ }^{52}$, Gregorio Nacianceno ${ }^{53}$ y Gregorio de $\mathrm{Nisa}^{54}$ —, la descripción realizada por Asterio —obispo de Amasea - de unas pinturas realistas ubicadas en un pórtico que se hallaba junto a la iglesia de Santa Eufemia ${ }^{55}$, y una carta atribuida a Nilo de Ancira ${ }^{56}$.

Tanto los escritos de estos eclesiásticos, coetáneos - y discrepantes - de Epifanio, como los del chipriota ponen de manifiesto que entonces existía, en Oriente, polémica acerca de las imágenes pictóricas antropomorfas, muchas de las cuales necesariamente debían corresponder a representaciones de santos. Son todavía algo más tardíos - y contemporáneos de Agustín- los primeros testimonios latinos conocidos que se muestran a favor de las pinturas martiriales, en los cuales se defiende incluso su función pedagógica: de ello cabe colegir que entonces estos frescos aún eran escasos en Occidente. En su Carmen 27 —escrito para la festividad de San Félix del 14 de enero del 403 (Desmulliez 1985, 60)_, Paulino de Nola escribe:

50 De mirac. s. Steph. protomart. libri, 2, 4, c. 851.

51 En este proceso, resulta especialmente significativa la documentación facilitada por las catacumbas romanas. Bisconti 1995, 272, escribe: «il giro d'orizzonte che descrive il panorama offerto dall'iconografia martiriale romana, alla luce di tutte queste considerazioni, si presenta estremamente povero di presenze per il periodo precedente al pontificato di Damaso, si propone con un "vuoto figurativo" direi assoluto e per lo più minato dal pericolo di falsi e false interpretazioni». Para el período preconstantiniano, ver también Provoost 1995. Cf. Ferrua-Carletti 1985.

52 Basilius Caes., In Barlaam mart., 3, c. 488-

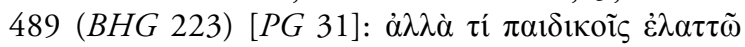

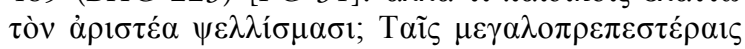

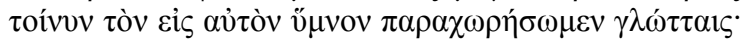

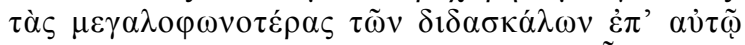

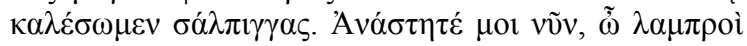

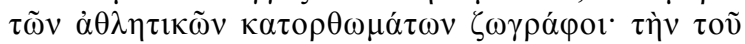

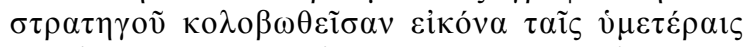

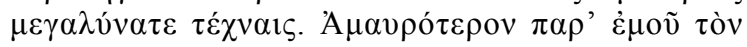

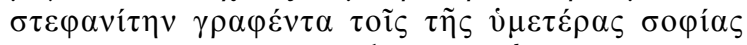

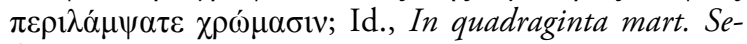
bastenses, 2, c. 508-509 (BHGa 1205) [PG 31].
53 Gregorius Naz., Carm. moral., 1, 2, 33, c. 929:

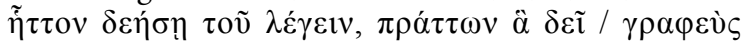

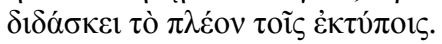

54 Gregorius Nyss., De s. Theodoro, c. 737-740 (BHG 1760) [PG 46]. Cf. Id., De deitate filii et spirit. sancti, c. 572.

55 Asterius Amas., Hom., 11, p. 153-155 (BHG ${ }^{a}$ 623-623a) [Datema, Leiden 1970]. Las escenas pintadas - en un pórtico cercano a la iglesia de la santaeran la comparecencia de la virgen ante el juez, la extracción de sus dientes, la aparición del signo de la cruz, y la quema. Asterio también atestigua - y reprueba- el hecho de llevar vestidos con escenas del Evangelio: Asterius Amas., Hom., 1, p. 8-9 [Datema, Leiden 1970]. Ver Maguire 1994.

56 Nilus Ancyr., Ep., 4, 61, c. 577-580 [PG 79]. En esta carta, se propone a Olimpiodoro - ver PLRE, II, 799, Olympiodorus 3- que subvencione la decoración pictórica de una basílica con escenas del Antiguo y Nuevo Testamento -y no con motivos de flora y fauna-. En relación con las epístolas atribuidas a Nilo, ver Cameron 1976. 
propterea nisum nobis opus utile totis / Felicis domibus pictura ludere sancta, / si forte adtonitas haec per spectacula mentes / agrestum caperet fucata coloribus umbra, / quae super exprimitur titulis, ut littera monstret / quod manus explicuit, dumque omnes picta uicissim / ostendunt releguntque sibi, uel tardius escae / sint memores, dum grata oculis ieiunia pascunt, / atque ita se melior stupefactis inserat usus, I dum fallit pictura famem; sanctasque legenti / historias castorum operum subrepit honestas / exemplis inducta piis; potatur hianti / sobrietas, nimii subeunt obliuia nini. / Dumque diem ducunt spatio maiore tuentes, I pocula rarescunt, quia per miracula tracto / tempore iam paucae superant epulantibus horae ${ }^{57}$.

También en el Carmen 28 - compuesto para el 14 de enero del 404 (ver Desmulliez 1985, 60) — se refiere Paulino a estas figuraciones pintadas: martyribus mediam pictis pia nomina signant, I quos par in uario redimiuit gloria sexu. I At geminas, quae sunt dextra laeuaque patentes, / binis historiis ornat pictura fidelis. / Vnam sanctorum conplent sacra gesta uirorum, / Iob uulneribus temptatus, lumine Tobit; / ast aliam sexus minor obtinet, inclita Iudith, / qua simul et regina potens depingitur Esther ${ }^{58}$.

Varios pasajes de su Ep. 32 —datada a finales del verano del 404 (ver Fabre 1949, 330) evidencian asimismo la valoración positiva que el poeta tenía de las imágenes pictóricas: realiza una extensa y detallada referencia a sus construcciones en Cimitile y Fondi, y a las de Sulpicio Severo en Primuliacum - para las cuales redacta versos con la intención de que fueran grabados ${ }^{59}$ - Éste había colocado, en el baptisterio, un retrato pintado del mismo Paulino, junto al de San Martín ${ }^{60}$ : quo minus moueor errore caritatis tuae, quia nullam beato illi fecisti iniuriam potiusque ad gloriam illius contulisti, ut contra despicabilem facies uenerabilis pingeretur, quo splendor eius conparatione tenebrarum clarius emicaret ${ }^{61}$. Además, esta carta proporciona una minuciosa descripción de las imágenes musivas ubicadas, por mandato del bordelés, en la bóveda de la basílica de Nola ${ }^{62}$ : absidem solo et parietibus marmoratam camera musiuo inlusa clarificat, cuius picturae hi uersus sunt ${ }^{63}$. En relación con la decoración de la basílica de Fondi, dice: quod tamen ea mihi maxime ratio persuasit, quia et in huius absida designatam picturam meus Victor adamauit et portare tibi uoluit, si forte unam de duabus elegeris in hac recentiore tua pingere, in qua aeque absidam factam indicauit ${ }^{64}$.

En su Peristephanon — publicado en el año 404 o 405 (ver Lana 1962, 43)_, Prudencio describe las escenas que había contemplado en la iglesia martirial de Imola:

stratus humi tumulo aduoluebar quem sacer ornat / martyr dicato Cassianus corpore. / Dum lacrimans mecum reputo mea uulnera et omnes / uitae labores ac dolorum acumina, / erexi ad caelum faciem, stetit obuia contra / fucis colorum picta imago martyris / plagas mille gerens, totos lacerata per artus, / ruptam minutis praeferens punctis cutem. I Innumeri circum pueri (miserabile uisu) / confossa paruis membra figebant stilis, / unde pugillares soliti percurrere ceras / scholare murmur adnotantes scripserant. / Aedituus consultus ait: "Quod prospicis, hospes, I non est inanis aut anilis fabula. I Historiam

\footnotetext{
57 Paulinus Nol., Carm. 27, v. 580-595, p. 288 [CSEL 30].

58 Paulinus Nol., Carm. 28, v. 20-27, p. 292 [CSEL 30].

$59 \mathrm{Al}$ igual que había hecho en Nola, Paulino también compone inscripciones métricas para acompañar y explicar las escenas pintadas en los edificios de Sulpicio Severo: Paulinus Nol., Ep., 32, 3-9, p. 277-285. Respecto a los versos que podían leerse en los santuarios
}

martinianos de Tours, y relacionados con sus escenas figuradas, ver Pietri 1983, 798-831.

60 Paulinus Nol., Ep., 32, 2-4, p. 276-278; 10, p. 285. Cf. Id., Ep., 30, 2, p. 262-263 [CSEL 29].

61 Paulinus Nol., Ep., 32, 2, p. 276-277.

62 Paulinus Nol., Ep., 32, 10, p. 286, 1. 8-21.

63 Paulinus Nol., Ep., 32, 10, p. 286, 1. 5-7.

64 Paulinus Nol., Ep., 32, 17, p. 291, 1. 20-24. 
pictura refert, quae tradita libris / ueram uetusti temporis monstrat fidem ${ }^{65}$ (...) haec sunt quae liquidis expressa coloribus, hospes, miraris, ista est Cassiani gloria» ${ }^{66}$.

Las representaciones pictóricas antropomorfas — no sólo de mártires— se documentan profusamente a partir del siglo v. Si nos ceñimos a Occidente, hallamos referencias, por ejemplo, en los escritos de Paulino de Périgueux ${ }^{67}$, Casiodoro ${ }^{68}$, Venancio Fortunato ${ }^{69}$, Gregorio de Tours ${ }^{70}$ y Gregorio Magno $^{71}$. Con este pontífice pueden darse ya por concluidas las reticencias a utilizar, en el ámbito latino, imágenes, escenas y secuencias pintadas en los edificios cultuales. Dice en su Ep. 9, 209: idcirco enim pictura in ecclesiis adhibetur, ut hi qui litteras nesciunt saltem in parietibus uidendo legant, quae legere in codicibus non ualent ${ }^{72}$. Y en la Ep. 11, 10: nam quod legentibus scriptura, hoc idiotis praestat pictura cernentibus, quia in ipsa ignorantes uident quod sequi debeant, in ipsa legunt qui litteras nesciunt; unde praecipue gentibus pro lectione pictura est ${ }^{73}$.

Durante el período anterior a la crisis iconoclasta, se acaba imponiendo completamente la legitimación didáctica del lenguaje figurativo y, en consecuencia, queda obsoleta y desautorizada la práctica culta y antigua, todavía defendida en el siglo vi por algunos obispos — caso de Sereno de Marsella ${ }^{74}$ y de Julián de Atramitio ${ }^{75}$ - : la oposición entre Escritura e imagen, fundamental durante la primera etapa del cristianismo, se había convertido ya en un estorbo para la propagación del mensaje bíblico, un claro indicador de los nuevos tiempos.

126].

65 Prudentius, Perist., 9, p. 326, v. 5-20 [CCSL

66 Prudentius, Perist., 9, p. 329, v. 93-94. Cf. asimismo 11, p. 370-375. Prescindimos del controvertido testimonio facilitado por el Dittochaeum. Al respecto, ver Pillinger 1980.

67 Paulinus Petric., De uita s. Martini, 1, v. 6-7, p. 19 (BHL 5617) [CSEL 16, 1].

68 Cassiodorus, Exp. psalm., 86, 1, p. 789-790 [CCSL 98].

69 Venantius Fortunatus, Vita s. Martini, 4, v. 665700, p. 369-370 (BHL 5624) [MGH aa 4, 1]. Fortunato nos dice que una lámpara estaba encendida ante la imagen de San Martín: hic paries retinet sancti sub imagine formam (...) lychnus adest, cuius uitrea natat ignis in urna (v. 690 y 693). Cf. Venantius Fortunatus, Carm., 10, 6, p. 234-238 [MGH aa 4, 1]. Ver PCBE, II, 1, 796, Felix 54. Ver Pietri 2001.

70 Gregorius Turon., Hist. libri, 2, 17, p. 64-65 [MGH srm 1, 1]: cuius coniux basilicam sancti Stephani suburbano murorum aedificauit. Quam cum fucis colorum adornare uelit, tenebat librum in sinum suum, legens historias actionis antiquae, pictoribus indicans, quae in parietibus fingere deberent; Id., Hist. libri, 7, 22, p. 341, 1. 10-13: cum autem presbiter, qui clauis ostei retenebat, clausis reliquis, recessissit, per illum salutaturii osteum introeuntes puellae cum reliquis pueris eius, suspiciebant picturas parietum rimabantque ornamenta beati sepulchri; quod ualde facinorosum relegiosis erat; Id., De uirt. s. Mar- tini episc., 1, 15, p. 147 (BHL 5618) [MGH srm 1, 2]: sibi quoque Rauenna atque in rethorica socii sui Felicis ex oleo, quod sub imagine picturae beati Martini in cicendile ardebat, dum tetigerunt oculos, lumen reddidisse confessus est; Id., In gloria mart., 21-22, p. 51 [MGH srm 1, 2].

71 Gregorius I, Ep., 9, 209, p. 768 (Jaffé, 1747) [CCSL 140A]; Id., Ep., 11, 10, p. 873-876 [ibid.]. El pontífice escribe al obispo Sereno de Marsella para recriminarle que hubiera destruido las imágenes de las iglesias. Ver: Duggan 1989; Chazelle 1990; Mariaux 1993; Pietri 2002. En relación con la información facilitada por Gregorio Magno relativa a las imágenes, cf. además: Gregorius I, Hom. in Cant. Cant., 4, p. 5, 1. 49-54 [CCSL 144]; Id., Ep., 9, 196, p. 750-751, donde se relata que un judío converso llamado Pedro —ver PCBE, II, 2, 1782, Petrus 93- había ocupado violentamente una sinagoga en Cagliari y colocado en ella una imagen de la Virgen. El metropolitano Hipacio de Éfeso —-fallecido después del 537/538 - escribe a un obispo sufragáneo suyo - Julián de Atramitio- que también había retirado diferentes objetos de las iglesias para evitar la idolatría. Hipacio justifica asimismo el uso de pinturas - y de estatuas - para la instrucción de los simples: Hypatius Ephes., Quaest. miscell., p. 127-129 [Diekamp, Roma 1938].

72 Gregorius I, Ep., 9, 209, p. 768, 1. 12-14.

73 Gregorius I, Ep., 11, 10, p. 874, 1. 23-26.

74 Ver n. 71.

75 Ver n. 71. Ver: Alexander 1952; Gero 1975. 
A partir de los testimonios relativos a las representaciones pictóricas, el contenido del c. 36 pseudoiliberritano no halla acomodo a principios de la cuarta centuria, cronología que le ha sido secularmente atribuida ${ }^{76}$. En cambio, sus dificultades exegéticas desaparecen si deja de ser ubicado en época preconstantiniana - o constantiniana-: nos decantaríamos por los últimos decenios del siglo IV o por los primeros del v. Con esta datación, similar a la que hemos propuesto para los c. 34 y 35, queda despejada la hermenéutica del c. 36, cuyo contenido encuentra sólidos apoyos: su formulación obedecería a la voluntad de atajar las figuraciones antropomorfas — sobre todo de $\operatorname{santos}^{77}$ - que entonces empezarían a ser visibles en paredes de edificios cultuales, tuvieran o no éstos un origen cementerial.

Tal disposición, que no puede ser anacrónica, se dirige en contra de una consecuencia dimanante del fenómeno martirial: al igual que los alumbrados diurnos de cirios o los comportamientos lascivos vinculados a las vigilias natalicias, las representaciones en las iglesias serían consideradas igualmente inadmisibles por todos aquellos que todavía se mantenían, resistiendo el ímpetu popular, fieles a los preceptos bíblicos y a la tradición. Además de constituir una «trilogía martirial», los c. 34, 35 y 36 conforman asimismo una «trilogía conservadora»: pertenecen a la misma corriente — finalmente perdedora- que Epifanio y Vigilancio ${ }^{78}$ encarnaban. Resulta evidente que quienes se mostraban acordes con la línea del presbítero galo, respecto a los cirios y a las vigilias, se opondrían también a que hubiera efigies en las iglesias, algo que resultaría difícil sin la autorización de los clérigos que se ocupaban de estos edificios. La interdicción del c. 36 necesariamente hace referencia a rostros humanos, habida cuenta de que en caso contrario no tendría ningún sentido ${ }^{79}$.

\section{BiBLIOGRAFÍA}

Alexakis, G., 1998, «The Dialogue of the Monk and Recluse Moschos concerning the Holy Icons, An Early Iconophile Text», DOP 52, 187-224.

Alexander, P.J., 1952, «Hypatius of Ephesus. A Note on Image Worship in the Sixth Century», HThR 45, 177-184.

Bargebuhr, F.P., 1991, The Paintings of the "New Catacomb» of the Via Latina and the Struggle of Christianity against Paganism, [Abhandlungen der Heidelberger Akademie der Wissenschaften, PhilosophischHistorische Klasse 2], Heidelberg: Winter.

Barnard, L., 1977, «The Theology of Images», en: A. Bryer, J. Herrin (ed.), Iconoclasm. Papers given at the Ninth Spring Symposium of Byzantine Studies, Birmingham: University of Birmingham, 17-33.

\footnotetext{
$76 \mathrm{Al}$ igual que sucede con los otros cánones pseudoiliberritanos, la erudición secular también ha interpretado el c. 36 a partir de dos premisas que no han resultado ciertas: la cronología preconstantiniana de los cánones atribuidos al "concilio de Elvira» y su carácter unitario. No sorprende que las propuestas exegéticas fundamentadas en los parámetros tradicionales hayan sido variadas y, en nuestra opinión, poco consistentes -en el mejor de los casos, se considera el c. 36 como la anticipación de una realidad muy posterior-. En relación con las explicaciones no analíticas de esta norma, baste con citar sólo las más recientes - cuyo texto recoge, por lo menos en buena medida, la extensa bibliografía anterior-: Rudolph 2004; Parisi 2003.
}

\footnotetext{
77 Además de las imágenes martiriales, en las iglesias también se acaban introduciendo representaciones de Cristo - y de la Virgen-, cuyas efigies quedarían igualmente incluidas en la prohibición del c. 36 . Ver n. 17-19, 25, 27, 31-32 y 42. Cf.: Schönborn 1976; Spera 1994.

78 Respecto a Vigilancio, remitimos a lo expuesto en Vilella 2008.

79 Así lo entendió también el autor de la interpolación que figura en la forma del c. 36 transmitida por la Colección Canónica Hispana: ne quod colitur et adoratur, in parietibus depingatur. Ver n. 5.
} 
Bavel, T.J. van, 1995, «The Cult of the Martyrs in St. Augustine. Theology versus Popular Religion?», en: M. Lamberigts, P. van Deun (ed.), Martyrium in Multidisciplinary Perspective: Memorial Louis Reekmans, [Bibliotheca Ephemeridum Theologicarum Lovaniensium 117], Leuven: Leuven University Press / Peeters, 351-361.

Baynes, N.H., 1955, «Idolatry and the Early Church», en: N.H. Baynes, Byzantine Studies and other Essays, London: Athlone Press, 116-143.

Bigham, S., 1992, Les chrétiens et les images. Les attitudes envers l'art dans l'Église ancienne, [Brèches Théologiques 13], Montréal: Éditions Paulines.

Bisconti, F., 1989, "Letteratura patristica e iconografia paleocristiana», en: A. Quacquarelli (ed.), Complementi interdisciplinari di Patrologia, Roma: Città Nuova, 367-412.

—, 1995, "Dentro e intorno all'iconografia martiriale romana: dal "vuoto figurativo" all' "immaginario devozionale"", en: M. Lamberigts, P. van Deun (ed.), Martyrium in Multidisciplinary Perspective: Memorial Louis Reekmans, [Bibliotheca Ephemeridum Theologicarum Lovaniensium 117], Leuven: Leuven University Press / Peeters, 247-292.

—, 2000, Temi di iconografia paleocristiana, [Sussidi allo Studio delle Antichità Cristiane 13], Città del Vaticano: Pontificio Istituto di Archeologia Cristiana.

Bovon, F., Geoltrain, P., 1997 (dir.), Ecrits apocryphes chrétiens, I, [Bibliothèque de la Pléiade 442], Paris: Gallimard.

Brown, P., 1983, Il culto dei santi. L'origine e la diffusione di una nuova religiosità, [Einaudi Paperbacks 144], Torino: Einaudi [traducción del original inglés, 1981, por L. Repici].

Brubaker, L. 1998, «Icons before Iconoclasm?», Morfologie sociali e culturali in Europa fra tarda Antichità e alto Medioevo, II, [Settimane di Studio 45], Spoleto: Centro Italiano di Studi sull'Alto Medioevo, 12151254.

Cameron, A., 1976, «The Authenticity of the Letters of St. Nilus of Ancyra», GRBS 17, 181-196.

Carletti, C., 1989, "Origine, committenza e fruizione delle scene bibliche nella produzione figurativa romana del III secolo", $\operatorname{Vet} C h r$ 26, 207-219.

Cavallera, F., 1922, Saint Jérôme. Sa vie et son oeuvre, I, 1-2, [Spicilegium Sacrum Lovaniense. Études et Documents 1-2], Louvain: Spicilegium Sacrum Lovaniense, Paris: Champion.

Chazelle, C.M., 1990, «Pictures, Books, and the Illiterate: Pope Gregory I’s Letters to Serenus of Marseilles», Word and Image 6, 138-153.

Courcelle, P., 1968², Recherches sur les Confessions de saint Augustin, Paris: De Boccard.

Croquisson, J., 1964, «L'iconographie chrétienne à Rome d'après le Liber pontificalis», Byzantion 34, 535606.

Dagron, G., 1979, «Le culte des images dans le monde byzantin», en: J. Delumeau (ed.), Histoire vécue du peuple chrétien, I, Toulouse: Privat, 133-160.

Delemaye, H., 1925, "Les recueils antiques de miracles des saints», $A B$ 43, 5-85 y 305-325.

—, 19273, Les légendes hagiographiques, [Subsidia Hagiographica 18], Bruxelles: Société des Bollandistes.

—, 19332, Les origines du culte des martyrs, [Subsidia Hagiographica 20], Bruxelles: Société des Bollandistes.

Delierneux, N., 2001, "Pratiques et vénération orientales et occidentales des images chrétiennes dans l'Antiquité tardive: à propos de quelques ambiguïtés», $R B P h 79,373-420$.

Desmulliez, J., 1985, «Paulin de Nole. Études chronologiques (393-397)», RecAug 20, 35-64.

Dовsснüтz, E. von, 1899, Christusbilder. Untersuchungen zur christlichen Legende, [Texte und Untersuchungen zur Geschichte der altchristlichen Literatur 18], Leipzig: Hinrichs.

Duchesne, L., 1955², Le Liber pontificalis. Texte, introduction et commentaire, I, Paris: De Boccard.

Duggan, L.W., 1989, "Was Art really the "Book of the Illiterate”?, Word and Image 5, 227-251.

Duval, Y., 2006, «Sur la genèse des libelli miraculorum», REAug 52, 97-112.

Fabre, P., 1949, Saint Paulin de Nole et l'amitié chrétienne, [Bibliothèque des Écoles Françaises d'Athènes et de Rome 167], Paris: De Boccard.

Ferrua, A., 1960, Le pitture della nuova catacomba di Via Latina, [Monumenti di Antichità Cristiana 8], Città del Vaticano: Pontificio Istituto di Archeologia Cristiana. 
Ferrua, A., Carletti, C., 1985, Damaso e i martiri di Roma: anno Damasi saeculari XVI, Città del Vaticano: Pontificia Commissione di Archeologia Sacra.

FÉvrier, P.-A., 1989, «À propos de la date des peintures des catacombes romaines», RAC 65, 105-133.

Finney, P.C., 1977, «Antecedents of Byzantine Iconoclasm: Christian Evidence before Constantine», en: J. Gutmann (ed.), The Image and the Word. Confrontations in Judaism, Christianity and Islam, [Religion and the Arts 4], Missoula: Scholars Press for the American Academy of Religion, 27-48.

—, 1987/1988, «Early Christian Art and Archaeology II (A.D. 200-500): A Selected Bibliography 19451985", JECS 6, 203-238.

Fiocchi Nicolai, V., Bisconti, F., Mazzoleni, D., 1999, Las catacumbas cristianas de Roma. Origen, desarrollo, aparato decorativo y documentación epigráfica, Regensburg: Schnell und Steiner.

Galavaris, A., 1981, The Icon in the Life of the Church. Doctrine - Liturgy - Devotion, [Iconography of Religions. Section 24; Christianity 8], Leiden: Brill.

Gero, S., 1975, «Hypatius of Ephesus on the Cult of Images», en: J. Neusner (ed.), Christianity, Judaism, an other Greco-Roman Cults. Studies for Morton Smith at Sixty, II, [Studies in Judaism in Late Antiquity 12, 2], Leiden: Brill, 208-216.

—, 1981, «The True Image of Christ: Eusebius' Letter to Constantia Reconsidered», JThS 32, 460-470.

Giordani, R., 1977, «Riflessi dell'arte figurativa nell'Octavius di Minucio Felice», VetChr 14, 21-39.

Grabar, A., 1967, El primer arte cristiano (200-395), Madrid: Aguilar [traducción del original francés, 1966, por L. Hernández].

—, 1968, Christian Iconography. A Study of Its Origins, [Bollingen Series 35, 10, The A.W. Mellon Lectures in the Fine Arts 10], Princeton: Princeton University Press [traducción del francés por T. Grabar].

GrigG, R., 1977, "Constantine the Great and the Cult without Images», Viator 8, 1-32.

Guyon, J., 1987, Le cimetière aux deux lauriers. Recherches sur les catacombes romaines, [Bibliothèque des Écoles Françaises d'Athènes et de Rome 264; Roma Sotterranea Cristiana 7], Roma: École Française de Rome, Città del Vaticano: Pontificio Istituto di Archeologia Cristiana.

Herrmann-Mascard, N., 1975, Les reliques des saints. Formation coutumière d'un droit, [Histoire institutionnelle et sociale 6], Paris: Klincksieck.

KitZinger, E., 1954, «The Cult of Images in the Age before Iconoclasm», DOP 8, 85-150.

—, 1980, "Christian Imagery: Growth and Impact», en: K. Weitzmann (ed.), Age of Spirituality: A Symposium, New York: The Metropolitan Museum of Art, 141-163.

Kötzsche Breitenbruch, L., 1976, Die neue Katakombe an der Via Latina in Rom. Untersuchungen zur Ikonographie der alttestamentlichen Wandmalereien, [Jahrbuch für Antike und Christentum. Ergänzungsband 4], Münster: Aschendorff.

Krautheimer, R., 1967, «The Constantinian Basilica», DOP 21, 115-140.

Lana, I., 1962, Due capitoli prudenziani: la biografia - la cronologia delle opere - la poetica, Roma: Studium.

Maguire, H., 1994, «Magic and Geometry in Early Christian Floor Mosaics and Textiles», JÖByz 44, 265274.

Mandouze, A. (dir.), 1982, Prosopographie chrétienne du Bas Empire, I: Prosopographie de l'Afrique chrétienne (303-533), Paris: Éditions du Centre National de la Recherche Scientifique [= PCBE, I].

Maraval, P., 1987, "Épiphane, "docteur des iconoclastes"», en: F. Boespflug, N. Lossky, Nicée II, 7871987: Douze siècles d’images religieuses, Paris: Le Cerf, 51-62.

Mariaux, P.A., 1993, "L'image selon Grégoire le Grand et la question de l'art missionnaire», CrSt 14, $1-12$.

Martindale, J.R., 1980, The Prosopography of the Later Roman Empire, II: A.D. 395-527, Cambridge: Cambridge University Press [= PLRE, II].

Martínez, G., Rodríguez, F., 1984, La Colección Canónica Hispana, IV, Madrid: Consejo Superior de Investigaciones Científicas.

Meigne, M., 1975, "Concile ou collection d'Elvire?», RHE 70, 361-387.

Menozzi, D., 1995, La Chiesa e le immagini. I testi fondamentali sulle arti figurative dalle origini ai nostri giorni, Milano: San Paolo. 
Murray, C., 1977, «Art and the Early Church», JThS 28, 303-344.

PARISI, M., 2003, "Ne picturae in ecclesia fiant. Storia e interpretazioni del canone 36 del concilio di Elvira dalla seconda metà dell'Ottocento alla fine del Novecento", Guttadauro 3, 145-172.

Perler, O., Maier, J.-L., 1969, Les voyages de Saint Augustin, Paris: Études Augustiniennes.

Pietri, C., Pietri, L. (dir.), 1999, Prosopographie chrétienne du Bas Empire, II: Prosopographie de l'Italie chrétienne (313-604), 1: A-K, Roma: École Française de Rome [= PCBE, II, 1].

—, 2000, Prosopographie chrétienne du Bas Empire, II: Prosopographie de l'Italie chrétienne (313-604), 2: L-Z, Roma: École Française de Rome [PCBE, II, 2].

Pietri, L., 1983, La ville de Tours du IVe au VIe siècle: naissance d'une cité chrétienne, [Collection de l'École Française de Rome 69], Roma: École Française de Rome.

—, 2001, «Vt pictura poesis: à propos de quelques poèmes de Venance Fortunat», Pallas 56, 175-186.

—, 2002, «Serenus de Marseille et Grégoire le Grand: une première querelle des images», en: M. Maritano (ed.), Historiam perscrutari. Miscellanea di studi offerti al prof. Ottorino Pasquato, [Biblioteca di Scienze Religiose 180], Roma: LAS, 327-341.

Pillinger, R., 1980, Die Tituli historiarum oder das sogenannte Dittochaeon des Prudentius. Versuch eines philologisch-archäologischen Kommentars, [Österreichische Akademie der Wissenschaften, PhilosophischHistorische Klasse 142], Wien: Österreichische Akademie der Wissenschaften.

Prigent, P., 1991, «Du bon usage de l'image dans l'église ancienne», RHPhR 71, 61-72.

Provoost, A., 1995, "Les représentations de martyrs à la fin de l'Antiquité», en: M. Lamberigts, P. van Deun (ed.), Martyrium in Multidisciplinary Perspective: Memorial Louis Reekmans, [Bibliotheca Ephemeridum Theologicarum Lovaniensium 117], Leuven: Leuven University Press / Peeters, 235-245.

Rice, D.T., 1957, The Beginnings of Christian Art, London: Hodder \& Stoughton.

Rudolph, C., 2004, "Communal Identity and the Earliest Christian Legislation on Art: Canon 36 of the Synod of Elvira», en: T. N. Kinder (ed.), Perspectives for an Architecture of Solitude: Essays on Cistercians, Art and Architecture in honour of Peter Fergusson, [Medieval Church Studies 11], Turnhout: Brepols, $1-7$.

SAXer, V., 1980, Morts, martyrs, reliques en Afrique chrétienne aux premiers siècles. Les témoignages de Tertullien, Cyprien et Augustin à la lumière de l’archéologie africaine, [Théologie Historique 55], Paris: Beauchesne.

Schönborn, C. von, 1976, L'icône du Christ. Fondements théologiques élaborés entre le Ier et le II concile de Nicée (325-787), [Paradosis 24], Freiburg: Éditions Universitaires.

Spera, L., 1994, «Un'immagine di Cristo nel santuario di Ippolito sulla via Tiburtina: note su alcuni casi di frequentazione tarda dei complessi martiriali a Roma», Bessarione 11, 39-51.

ŜPIDLík, T., 1989, «Le concept de l'image chez les pères jusqu'au concile de Nicée II», en: E.A. Livingstone (ed.), Papers presented to the Tenth International Conference on Patristic Studies Held in Oxford, 1987, [Studia Patristica 23], Leuven: Peeters, 74-86.

—, 1991, "Mots, images, icônes», Destins de l'image. Nouvelle Revue de Psychanalyse 44, 151-168.

ThÉrel, M.-L., 1973, Les symboles de l'ecclesia dans la création iconographique de l'art chrétien du III au $V I^{e}$ siècle, Roma: Edizioni di Storia e Letteratura.

Thüмmel, H. G., 1984, «Eusebios’ Brief an Kaiserin Konstantia», Klio, 66, 210-222.

TRISTAN, F., 1996, Les premières images chrétiennes: du symbole à l'icône, II s.-VI s., Paris: Fayard.

Vilella, J., 2000, «Biografía crítica de Orosio», JbAC 43, 94-121.

—, 2007, «Las sanciones de los cánones pseudoiliberritanos», SEJG 46, 5-87.

—, 2008, «In cimiterio: dos cánones pseudoiliberritanos relativos al culto martirial», Gerión 26, 491-527.

Vilella, J., Barreda, P.-E., 2002, «Los cánones de la Hispana atribuidos a un concilio iliberritano: estudio filológico», I concili della cristianità occidentale. Secoli III-V, [Studia Ephemeridis Augustinianum 78], Roma: Institutum Patristicum Augustinianum, 545-579.

—, 2006, «¿Cánones del concilio de Elvira o cánones pseudoiliberritanos?», Augustinianum 46, 285-373.

Vooght, P. de, 1939, «Les miracles dans la vie de saint Augustin», RecTh 11, 5-16. 